\title{
An Introduction to the Theory of Linear Systems
}

\author{
R. Fratila
}

U.S. Naval Electronic Systems Command, Washington, D.C.

For sale by the Superintendent of Documents, U.8. Government Printing Office Washington, D.C. 20402 - Price $\$ 1.60$

Stock No. 008-050-00148-7 